\title{
One-Step Fabrication of Biocompatible Multifaceted Nanocomposite Gels and Nanolayers
}

Fuat Topuz, ${ }^{* \dagger, \ddagger(0) ~ M a t t h i a s ~ B a r t n e c k, ~}{ }^{\S}$ Yu Pan, and Frank Tacke ${ }^{\S}$

${ }^{\dagger}$ DWI-Leibniz Institute for Interactive Materials e.V., RWTH Aachen University, Forkenbeckstrasse 50, 52074 Aachen, Germany

${ }^{\ddagger}$ UNAM-National Nanotechnology Research Center, Bilkent University, 06800 Ankara, Turkey

${ }^{\S}$ Department of Medicine III, Medical Faculty, RWTH Aachen University, Pauwelsstr. 30, 52074 Aachen, Germany

"Biomedical Engineering, Biointerface Laboratory, RWTH Aachen University, 52074 Aachen, Germany

\section{Supporting Information}

ABSTRACT: Nanocomposite gels are a fascinating class of polymeric materials with an integrative assembly of organic molecules and organic/inorganic nanoparticles, offering a unique hybrid network with synergistic properties. The mechanical properties of such networks are similar to those of natural tissues, which make them ideal biomaterial candidates for tissue engineering applications. Existing nanocomposite gel systems, however, lack many desirable gel properties, and their suitability for surface coatings is often limited. To address this issue, this article aims at generating multifunctional nanocomposite gels that are injectable with an appropriate time window, functional with bicyclononynes (BCN), biocompatible and slowly degradable, and possess high mechanical strength. Further, the in situ network-forming property of the proposed system allows the fabrication of ultrathin nanocomposite coatings in the submicrometer range with tunable wettability and roughness. Multifunctional nanocomposite gels were fabricated under cytocompatible conditions ( $\mathrm{pH} 7.4$ and $\mathrm{T}=37^{\circ} \mathrm{C}$ ) using laponite clays, isocyanate (NCO)-terminated $\mathrm{sP}(\mathrm{EO}$-stat-PO) macromers, and clickable BCN. Several characterization techniques were employed to elucidate the structureproperty relationships of the gels. Even though the NCO-sP(EO-stat-PO) macromers could form a hydrogel network in situ on contact with water, the incorporation of laponite led to significant improvement of the mechanical properties. BCN motifs with carbamate links were used for a metal-free click ligation with azide-functional molecules, and the subsequent gradual release of the tethered molecules through the hydrolysis of carbamate bonds was shown. The biocompatibility of the hydrogels was examined through murine macrophages, showing that the material composition strongly affects cell behavior.

\section{INTRODUCTION}

Hydrogels are water-filled swollen polymeric matrices with diverse physical properties, which can be engineered to resemble any form. This enables their use as biosensors, cellscaffolds, and drug delivery devices. ${ }^{1-4}$ However, their mechanical weakness acts as an obstacle in many applications, such as tissue regeneration scaffolds in load-bearing tissues and wound sealants that require higher resistance to external deformation. Most hydrogels consist of a random arrangement of a large number of covalent cross-links and thus are brittle on exposure to an external force because of a poor energy dissipation mechanism in the gel network. ${ }^{5,6}$ In addition to the permanent cross-links, the incorporation of physical links (e.g., hydrophobic interactions, hydrogen bonding, supramolecular links, etc.) can significantly improve mechanical properties and leads to an efficient energy dissipation mechanism. Such physical bonds can break and reform dynamically before the fracture of the molecular backbone, generating soft and ductile networks with compressibility, stretchability, and recoverability due to the presence of intermolecular noncovalent interactions. $^{7-9}$ In this context, several approaches have been developed to improve energy dissipation mechanisms, such as (i) sliding-ring gels, (ii) double-network gels, (iii) macromolecular microsphere composite gels, and (iv) hydrogels with hydrophobic domains. ${ }^{10-14}$ Additionally, the incorporation of nanoparticles into hydrogels can considerably enhance the mechanical properties of polymeric networks by acting as additional cross-linking domains. ${ }^{10}$ In this regard, silicate-based hybrid gels have shown astonishing properties, which aid in the design of novel materials for drug delivery, tissue engineering, and biomedical imaging applications due to the enhanced surface interaction of polymers with silicate nanoparticles, such as laponites. ${ }^{11}$

Received: October 6, 2016

Revised: December 14, 2016

Published: December 15, 2016 

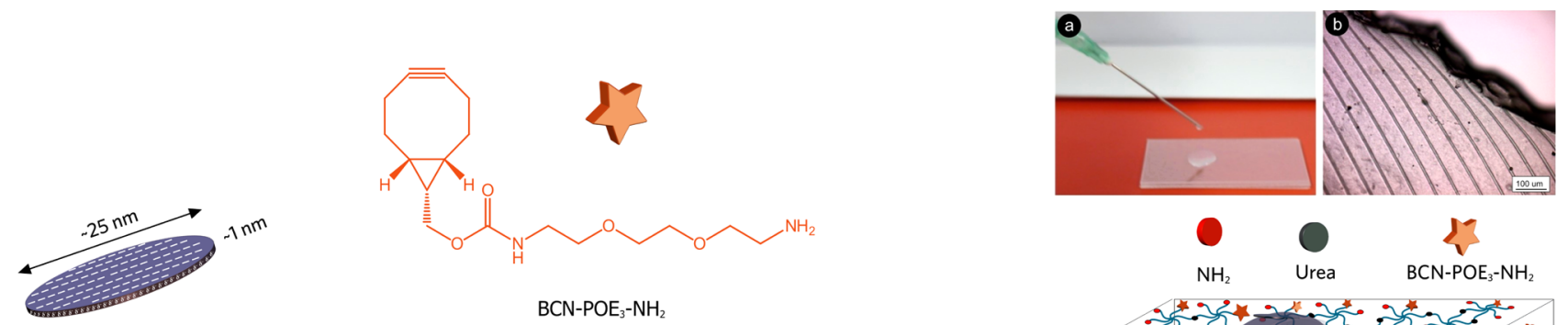

$\mathrm{BCN}-\mathrm{POE}_{3}-\mathrm{NH}_{2}$
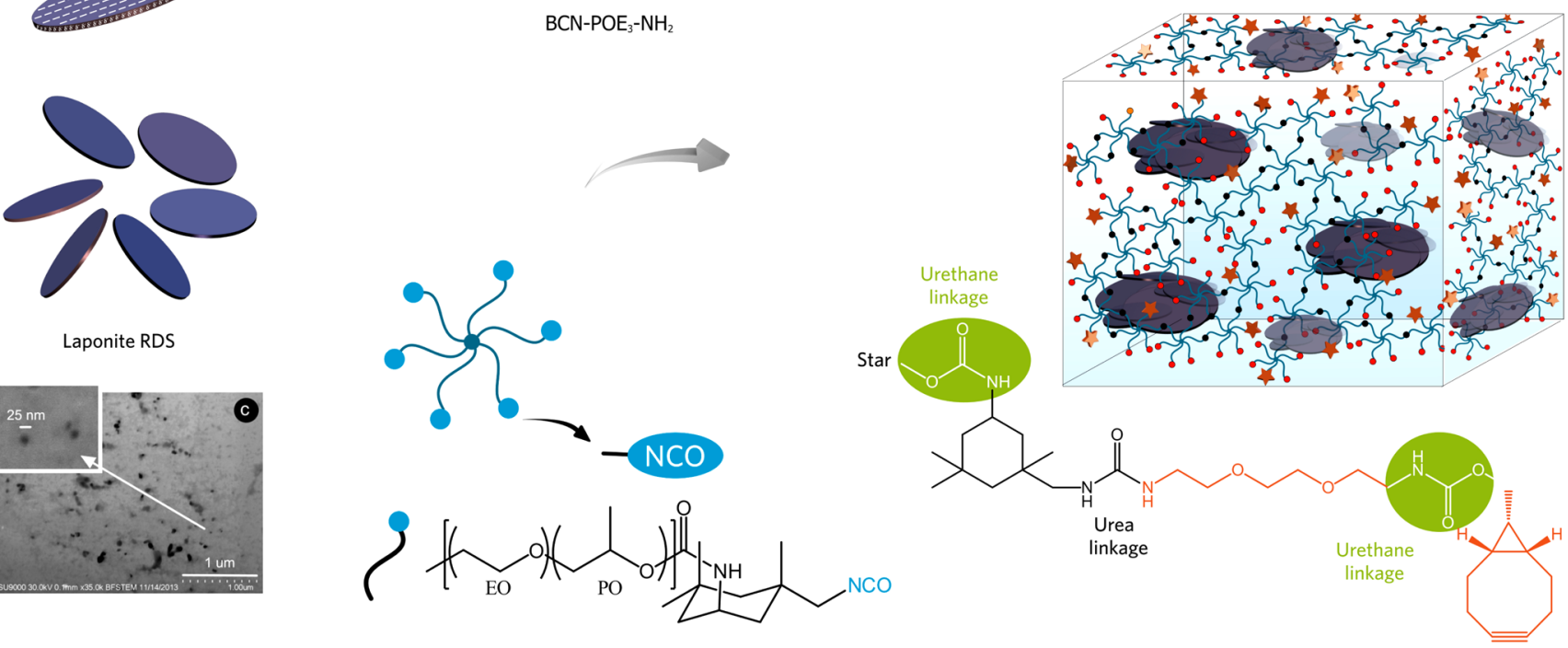

NCO-sP(EO-stat-PO)

Figure 1. Schematic illustration of $\mathrm{BCN}$-functional biodegradable laponite-NCO-sP(EO-stat-PO) gel fabrication. Inset images show the (a) injectability and (b) patternability of the hydrogel system using a PDMS replica $\left(c_{\mathrm{sP} \text { (EO-stat-PO) }}=10 \mathrm{wt} \%, c_{\text {clay }}=1 \mathrm{wt} \%\right)$. (c) BF-STEM image showing laponite disks on a TEM grid.

Laponites $\left.\left(\mathrm{Na}_{0.7}^{+}\left[\mathrm{Mg}_{5.5} \mathrm{Li}_{0.3}\right) \mathrm{Si}_{\mathrm{g}} \mathrm{O}_{20}(\mathrm{OH})_{4}\right]\right)_{0.7}^{-}$are compositionally similar to bioactive glasses and have the shape of a nanodisk with an average diameter of $25 \mathrm{~nm}$ and a thickness of $1 \mathrm{~nm} .{ }^{15}$ They are particularly appealing with respect to natural clays due to their excellent uniform dispersibility. ${ }^{16}$ Laponite acts as multifunctional physical cross-linking points for polymers, leading to a hydrogel network. Earlier studies on laponite revealed that these particles could be degraded or dissolved into nontoxic products $\left(\mathrm{Na}^{+}, \mathrm{Si}(\mathrm{OH})_{4}, \mathrm{Mg}^{2+}, \mathrm{Li}^{+}\right)$in the $\mathrm{pH}$ range of $7.3-8.4$, resulting in ortho-silicic acid $\left(\mathrm{Si}(\mathrm{OH})_{4}\right)$ as the major dissolution product. ${ }^{17}$ Ortho-silicic acid can be absorbed by the body and is found in numerous human tissues and organs, such as bone, tendon, aorta, liver, and kidney. ${ }^{18,19}$ Further, a novel study by Khademhosseini and co-workers reported that these bioactive nanoparticles can promote the in vitro osteogenic differentiation of human mesenchymal stem cells (hMSCs) in the absence of osteoinductive factors, such as bone morphogenetic proteins2 (BMP-2) or dexamethasone. ${ }^{20}$ Recently, a mix of laponite clays and gelatin was successfully implemented in the development of shear thinning nanocomposite systems for hemorrhage treatment with a significant decrease in vitro blood clotting times of $77 \% .^{21}$ In addition, laponite clays were employed with amino-functional molecules having guanidinium ion $\left(\mathrm{Gu}^{+}\right)$pendants to obtain physically cross-linked gel networks. 22,23

The implementation of organic or inorganic nanoparticles (e.g., titanate(IV) nanosheets (TiNSs, sodium montmorillonite (NaMMT) and Ag nanoparticles) with polymers in various forms has led to various functional materials for medical and industrial applications. ${ }^{24-31}$ Existing nanocomposite gel sys- tems are mostly based on mechanically strong hydrogel networks together with biocompatible, responsive, or injectable forms. $^{32-36}$ It remains a great challenge to produce gel networks that combine these properties with a unique functional structure and a nanolayer-forming ability while the network gradually disintegrates over time through hydrolysis. To address this limitation, this work aims at generating nanocomposite hydrogels that are injectable within an appropriate time window, functional with $\mathrm{BCNs}$, biocompatible and slowly degradable, and have high mechanical strength (Figure 1). The presented system can easily yield biodegradable nanocomposite constructs as hydrogels or ultrathin 3D layers in the submicrometer range, depending on the fabrication route, through in situ gelation of precursors. Furthermore, covalently embedded BCN motifs allow a dynamic alteration of the threedimensional network structure with a metal-free click reactivity toward azides, which enables the release of the tethered molecules such that the delivery will be dictated by the gradual hydrolysis of carbamate links.

\section{EXPERIMENTAL SECTION}

Materials. Laponite clay (laponite RDS) was purchased from Rockwood Additives Ltd. Star-shaped hydroxyl-terminated polyethers with a backbone of $80 \%$ ethylene oxide and $20 \%$ propylene oxide and a molecular weight of $12000 \mathrm{~g} / \mathrm{mol}(\mathrm{PDI}=1.15)$ were obtained from Dow Chemicals (Netherlands), and the hydroxyl terminal groups were functionalized with isocyanate (NCO) groups. Isophorone diisocyanate (IPDI) was purchased from Sigma-Aldrich and double distilled before use. $N-(1 R, 8 S, 9 s)$-Bicyclo[6.1.0]non-4-yn-9-ylmethyloxycarbonyl 1,8-diamino-3,6-dioxaoctane (BCN-POE $-\mathrm{NH}_{2}$ ) was obtained from Synaffix BV (Netherlands). Azide fluorescent dye (EterneonAzide) was purchased from Jena Chemicals (Germany). Dulbecco's 
phosphate-buffered saline (calcium and magnesium free, from SigmaAldrich) was used.

Synthesis of the Isocyanate-Terminated sP(EO-stat-PO). The isocyanate functionalization of the star polymers was performed as previously described. ${ }^{37}$ The hydroxyl terminated sP(EO-stat-PO)s $\left(M_{\mathrm{n}}\right.$ $=12000 \mathrm{~g} / \mathrm{mol}$; PDI = 1.15) were functionalized with isophorone diisocyanate (IPDI) in a solvent-free process at $50{ }^{\circ} \mathrm{C}$ for 4 days under an inert atmosphere. Short-path distillation was used to remove the excess IPDI. Size-exclusion chromatography of the product (NCO$\mathrm{sP}(\mathrm{EO}-$ stat-PO) $)$ confirmed that no dimer or trimer formation took place after the functionalization.

Fabrication of Multifunctional Nanocomposite Hydrogels. Laponite aqueous solutions were prepared before use at the preset concentrations in PBS under vigorous stirring for at least $1 \mathrm{~h}$. The NCO-sP(EO-stat-PO)s, BCN motifs, and an aqueous dispersion of laponite were mixed. Afterward, the solutions were taken into syringes of $4.7 \mathrm{~mm}$ inner diameter or poured between the plates of a rheometer. The mixture was held overnight at $37{ }^{\circ} \mathrm{C}$ to complete the cross-linking reactions. During the preparation of hydrogels, the concentrations of both laponite and NCO-sP(EO-stat-PO) were systematically changed.

Rheological Analysis. Dynamic rheological measurements were performed with a rheometer (DHR, TA Instruments). Gelation measurements were carried out between the plates (parallel plate, diameter $(D)=40 \mathrm{~mm}$, gap size $=500 \mu \mathrm{m})$ at $37^{\circ} \mathrm{C}$, and during the measurements, a thin film of silicone oil was used to minimize solvent evaporation. Throughout the measurements, strain $(\gamma)$ and frequency $(\omega)$ were respectively set to 0.1 and $6.28 \mathrm{rad} / \mathrm{s}$ to ensure that the oscillatory deformation is within the linear viscoelastic range. A frequency-sweep test was performed in the frequency range of $0.06-$ $600 \mathrm{rad} / \mathrm{s}$ at strain $(\gamma)=0.1$. Thereafter, a strain-sweep test was carried out in the strain range of $0.01-10$ at frequency $(\omega)=6.28 \mathrm{rad} / \mathrm{s}$. During the measurements, temperature $(T)$ was kept at $25^{\circ} \mathrm{C}$. Stressrelaxation experiments were carried out at various $\gamma$.

Swelling and Degradation Tests. Hydrogel samples were prepared in syringes and then immersed in PBS or water at room temperature to reach swelling equilibrium (i.e., 1 week) by replacing the medium every day. The swelling ratios $\phi$ and $m_{\text {rel }}$ at the seventh day were calculated as

$$
\begin{aligned}
& \phi=\left(D / D_{\mathrm{o}}\right)^{3} \\
& m_{\text {rel }}=\left(\mathrm{m} / \mathrm{m}_{\mathrm{o}}\right)
\end{aligned}
$$

where $D$ (or $m$ ) and $D_{\mathrm{o}}$ (or $m_{\mathrm{o}}$ ) are the diameter (or mass) of the gel sample at a given time $(t)$ and just after its preparation, respectively.

The degradation of the hydrogel samples in PBS at $37{ }^{\circ} \mathrm{C}$ was monitored over gel weights after the lyophilization of the samples.

Thermogravimetric Analysis (TGA). TGA experiments were conducted using a TG 209 with a TA-System Controller TASC 414/2 from Netzsch. The measurements were performed under a nitrogen atmosphere in the range of $25-500{ }^{\circ} \mathrm{C}$ with a heating rate of $10^{\circ} \mathrm{C} /$ min. Data analysis was performed with Proteus software (ver. 6.1, from Netzsch Instruments).

Scanning Electron Microscopy (SEM). Hydrogel samples were kept in water for a couple of days and then lyophilized. The internal structures of the gels were directly imaged by ultra-high-resolution SEM (Hitachi SU9000 at $1 \mathrm{kV}$ ) without any sputtering. The EDX analysis of the lyophilized gels was carried out at $15 \mathrm{kV}$ with a Hitachi SEM 3000N.

Dynamic Mechanical Analyzer (DMA). The mechanical properties of the swollen hydrogel samples were examined using a dynamic mechanical analyzer (DMA Q800, TA Instruments) using a submersion clamp. Cylindrical-shaped hydrogel samples were exposed to stress-strain tests with an incremental speed of $0.5 \mathrm{~N} / \mathrm{min}$. The compression modulus was determined as the slope of the stress-strain curve at low strains $(<20 \%)$. The stress-at-beak $\left(\sigma_{\mathrm{B}}\right)$ and strain at-beak $\left(\varepsilon_{\mathrm{B}}\right)$ were determined using Universal Analyzer Software (TA Instruments).

Wide-Angle X-ray Scattering (WAXS). WAXS analysis was done using an Empyrean setup from PANalytical. A Cu X-ray tube (line source of $12 \times 0.04 \mathrm{~mm}^{2}$ ) provided $\mathrm{Cu} \mathrm{K} \alpha$ radiation with $\lambda=0.1542$ $\mathrm{nm}$. The $\mathrm{K} \beta$ line was removed by a Ni filter. The source and detector moved in the vertical direction around a fixed horizontal sample. After passing a divergence slit of $1 / 8^{\circ}$ and an antiscatter slit of $1 / 4^{\circ}$, the beam reached the sample at the center of a phi-chi-z stage. In the Bragg-Bretano geometry used, the beam was refocused at a secondary divergence slit of $1 / 4^{\circ}$. Finally, the signal was recorded by a pixel detector $(256 \times 256$ pixels of $55 \mu \mathrm{m})$ as a function of the scattering angle $2 \theta$. Subsequently, the peak positions were calculated from $q=$ $2 \pi / d=(4 \pi / \lambda) \sin \theta$, in which $q$ is the scattering vector. The detector was used in a scanning geometry that allowed all rows to be used simultaneously. To reduce the background, the divergent beam perpendicular to the scattering plane was controlled by a $4 \mathrm{~mm}$ mask by restricting the width of the beam at the sample position to ca. 10 $\mathrm{mm}$. In addition, the perpendicular divergence was restricted by soller slits to angles $\leq 2.3^{\circ}$.

For each measurement, the sample height was optimized. Scans were made with $2 \theta$, the detector axis, moving at twice the rate of the $\theta$ axis of the incident beam. The calibration was checked using a Si reference sample.

Differential Scanning Calorimetry (DSC). DSC analysis was performed on a Netzsch 204 differential scanning calorimeter. The freeze-dried gels $(\sim 5 \mathrm{mg})$ were put in closed aluminum crucibles together with an empty crucible as a reference. The samples were cooled from 25 to $-70{ }^{\circ} \mathrm{C}$ at a rate of $10^{\circ} \mathrm{C} \mathrm{min}^{-1}$ and subsequently warmed to $25^{\circ} \mathrm{C}$ at the same rate.

Fabrication of Nanocomposite Gel Nanolayers. Substrate Cleaning and UV/Ozone Treatment. Glass substrates were first cleaned by sonication in acetone, water, and isopropanol ( $5 \mathrm{~min}$ each). Subsequently, the substrates were dried in a stream of nitrogen. The surface activation was achieved by a UV/ozone treatment for $30 \mathrm{~min}$. After this step, the water contact angles were below the detection limit. The substrates were then used for amino functionalization.

Aminosilylation of the Glass Substrates. After activation with UV/ ozone treatment, the substrates were treated with 3-aminopropyltrimethoxysilane $(100 \mu \mathrm{L})$ in a desiccator at $5 \mathrm{mbar}$ for $1 \mathrm{~h}$. After the removal of 3-aminopropyl-trimethoxysilane, the substrates were kept at $10^{-2} \mathrm{mbar}$ for one more hour to remove unbound aminosilane compounds.

Fabrication of Ultrathin Hydrogel Coatings. The NCO-terminated $\mathrm{SP}(\mathrm{EO}-$ stat-PO)s were dissolved in dry THF under an inert gas atmosphere. Then, the solutions were transferred to the clean room. After the addition of laponite dispersions (i.e., prepared in water), they were mixed for $1 \mathrm{~min}$ and dropped onto aminosilylated surfaces. A thin hydrogel layer was generated on the amino-functionalized substrates using a spin coater by acceleration within $5 \mathrm{~s}$ to the final rotation speed at $2500 \mathrm{rpm}$ and kept rotating for $40 \mathrm{~s}$.

Drug Releasing Study. Azide-modified fluorescence dye (EterneonAzide, Jena Chemicals) was selected as a model molecule for the drug release study. $\mathrm{BCN}$ and azide dye were mixed for $2 \mathrm{~h}$ to ensure complete reaction, and an aqueous mixture of NCO-sP(EO-stat-PO) and laponite was added afterward. Once the nanocomposite gel was formed, the release test was carried out in $5 \mathrm{~mL}$ of PBS solution. At different time intervals, $2 \mathrm{~mL}$ of solution was taken and measured by a fluorescence spectrophotometer (Horiba Instruments, Germany) and $2 \mathrm{~mL}$ of fresh PBS was replenished.

Cell Isolation and Culture. Bone marrow cells were isolated from the femurs and tibias of eGFP mice that were housed under specific pathogen-free conditions as approved by German legal authorities. Bones were perfused using PBS. To obtain fibroblast-conditioned medium (FCM), L929 fibroblasts were cultured in RPMI medium containing $10 \%$ fetal calf serum (FCS) for 3 days. For the generation of bone marrow derived macrophages (BMM), bone marrow cells were cultured in RPMI medium containing $10 \%$ FCS and $20 \%$ FCM. After 3 days, $20 \%$ of the medium was replaced. When the plates were covered with cells completely, the supernatant was replaced, and one plate of cells was split on four other plates. Cells were cultured in a humidified incubator at $37{ }^{\circ} \mathrm{C}$ and $5 \% \mathrm{CO}_{2}$. For the incubation with the materials, $0.2 \times 10^{6}$ cells in $1 \mathrm{~mL}$ of RPMI with $10 \%$ FCS and $20 \%$ FCM were added to the materials. 

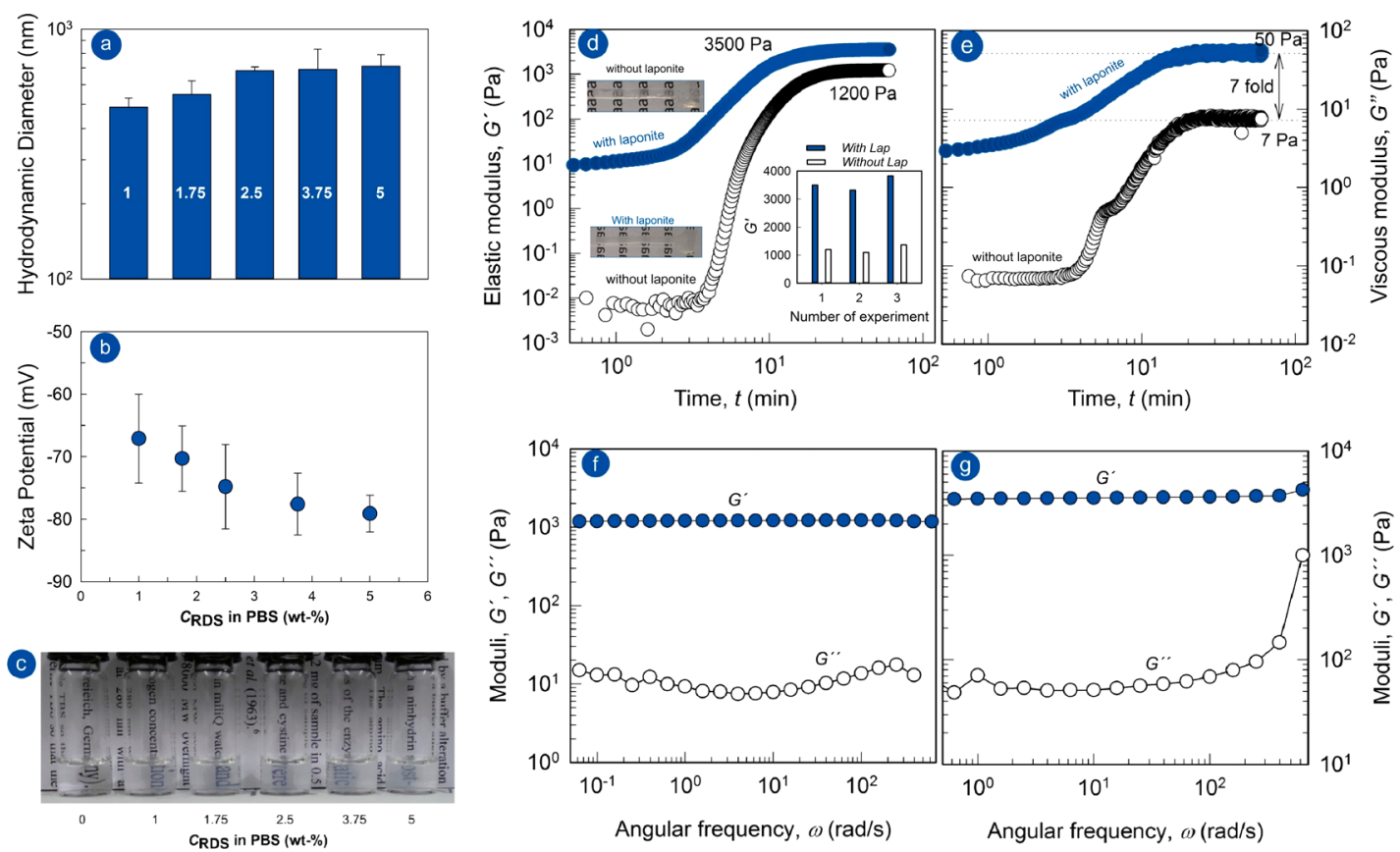

Figure 2. Characterization of aqueous laponite solutions and rheological properties of the functional nanocomposite hydrogels: (a) hydrodynamic diameters and (b) the zeta potentials of aqueous laponite solutions in PBS. (c) Increasing turbidity of the aqueous laponite solutions in PBS (from left to right). (d) Elastic modulus $G^{\prime}$ and (e) viscous modulus $G^{\prime \prime}$ during the cross-linking of the NCO-sP(EO-stat-PO) prepolymers having BCN motifs $(0.22 \mathrm{mmol}$; 0.16 equiv of star molecule that corresponds to one arm per $\mathrm{sP}(\mathrm{EO}$-stat-PO) molecule) with/without 1 wt \% laponite. Insets show (i) the batch-to-batch variations of $G^{\prime}$ and (ii) gel pictures of the samples with/without $1 \mathrm{wt} \%$ laponite. (f, g) Frequency sweeps of the respective hydrogels. $c_{\mathrm{sP}(\mathrm{EO}-\text {-stat } \mathrm{PO})}=10 \mathrm{wt} \%$, and $c_{\text {lap }}=1 \mathrm{wt} \%$. During rheological measurements, the gelation temperature $(T)$ was kept at $37{ }^{\circ} \mathrm{C}$.

Microscopy. A DMI6000B microscope equipped with a DFC 360FX camera was used (Leica Microsystems, Vienna, Austria). Fluorescence microscopy settings were adjusted based on the fluorescence of the cells on 24-well polystyrene plates after the designated time intervals. Propidium iodide was obtained from R\&D Systems (Minneapolis, MN, USA).

\section{RESULTS AND DISCUSSION}

Synthesis and Characterization of Multifunctional Nanocomposite Hydrogels. Laponite RDS is a synthetic hectorite-like clay decorated with pyrophosphate ions $\left(\mathrm{P}_{2} \mathrm{O}_{7}{ }^{4-}\right)$, leading to negative charges on all faces. Since there are repulsive electrostatic interactions among the clay particles that force them to stay separate even at moderate concentrations, the clays could easily be dispersed in water without forming a gel-like structure. The aqueous solution of laponite RDS has a low viscosity so that it can serve as an injectable dispersion. ${ }^{38}$ In PBS, the aqueous solution of laponite RDS became turbid because of the formation of clay aggregates by ionic interactions. The aggregate formation was confirmed by DLS: The size of the aggregates ranged from 300 to $800 \mathrm{~nm}$ with increasing concentration of laponite (Figure 2a). The presence of the clay aggregation was also supported by a nonlinear increase of the zeta potential values of the aqueous laponite solution with concentration (Figure $2 \mathrm{~b}$ ). After mixing the aqueous clay solution with NCO-sP(EO-stat-PO)s and $\mathrm{BCN}$, functional nanocomposite hydrogels were successfully produced at $37{ }^{\circ} \mathrm{C}$ and $\mathrm{pH}$ 7.4. The cross-linking reactions were monitored by the elastic $\left(G^{\prime}\right)$ and viscous moduli $\left(G^{\prime \prime}\right)$ of the gel solution during the evolution of the network at low amplitude strains. The formation of a BCN-functional NCO$\mathrm{sP}(\mathrm{EO}-$ stat-PO) hydrogel in the presence and absence of laponite is shown in Figure 2d,e, where both moduli $\left(G^{\prime}\right.$ and $\left.G^{\prime \prime}\right)$ were recorded over time $(t)$. Terminal isocyanate groups
(NCO) are highly susceptible to hydrolysis and transform into amine groups $\left(\mathrm{NH}_{2}\right)$ over unstable carbamic acids. Simultaneously, the newly formed amino groups react with the remaining isocyanates, resulting in the formation of a hydrogel network. This cross-linking mechanism was also able to generate microstructured hydrogels using a polydimethylsiloxane (PDMS) replica, on which an aqueous solution of gel components was poured and left for cross-linking. Subsequently, the cross-linked nanocomposite material was separated from the replica, and a micropatterned hydrogel structure could be fabricated at a mixture of $10 \mathrm{wt} \% \mathrm{sP}(\mathrm{EO}-$ stat-PO) and 1 wt \% laponite (Figure 1, inset b). This state clearly demonstrates the suitability of the gel system for patterning applications.

In the absence of laponite, the NCO-sP(EO-stat-PO) prepolymers at $10 \mathrm{wt} \%$ reacted within $20 \mathrm{~min}$, reaching a plateau at an elastic modulus $\left(G^{\prime}\right)$ of $1200 \mathrm{~Pa}$ and viscous modulus $\left(G^{\prime \prime}\right)$ of $7 \mathrm{~Pa}$ (Figure $2 \mathrm{~d}$ ). However, following the addition of $1 \mathrm{wt} \%$ laponite into the polymerization medium, a 3 -fold increase in $G^{\prime}$ was observed, demonstrating strong interactions between the clay and the polymer network. These gelation experiments were repeated three times, and similar values for $G^{\prime}$ were measured (Figure $2 \mathrm{~d}$, inset). Thus, the reinforcement of the $\mathrm{s} \mathrm{P}(\mathrm{EO}-$ stat-PO) networks with laponite incorporation was evident. The hydrogels exhibited frequencyindependent $G^{\prime}$ in the range of angular frequency $(\omega)$ from 0.06 to $600 \mathrm{rad} / \mathrm{s}$, suggesting the formation of mechanically strong networks. On the other hand, a significant rise in $G^{\prime \prime}$ suggested that clay particles not only increased the strength of the gel but also impacted the toughness of the hydrogel (Figure $2 \mathrm{e})$. The toughness may be associated with the energydissipating properties of the cross-linked network. Tan $\delta$ (loss factor, $\left.G^{\prime \prime} / G^{\prime}\right)$ represents polymer adhesive bonds that are 


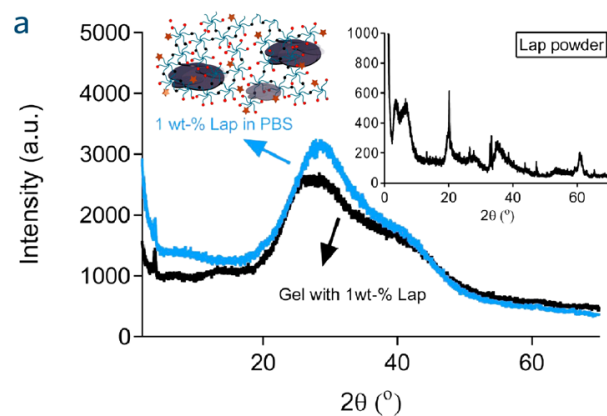

b

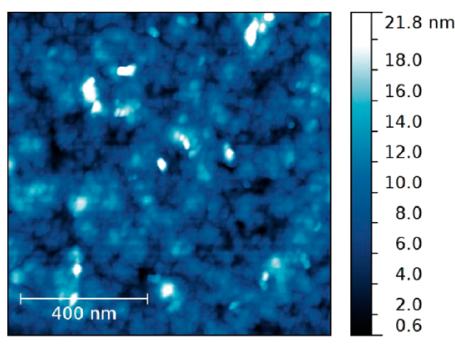

C

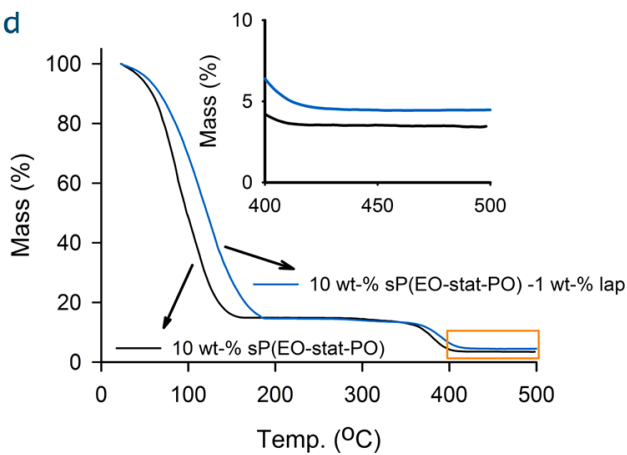

Figure 3. Characterization of the $\mathrm{sP}(\mathrm{EO}$-stat-PO) hydrogels. (a) XRD patterns of the clay dispersion in $\mathrm{PBS}$ and the hydrogel with 1 wt \% laponite. Insets show the proposed distribution of clays in the gel matrix and the XRD pattern of the laponite powder. (b) AFM micrograph of a 1 wt $\%$ laponite dispersion (in PBS) on a mica surface after spin-coating. (c) DSC curves for lyophilized gels, revealing the glass transition temperature $\left(T_{\mathrm{g}}\right)$ to be $-59.6{ }^{\circ} \mathrm{C}$ and the crystallization of freezing bound water between -32.3 and $-28.8{ }^{\circ} \mathrm{C}$ and the corresponding melting at $0{ }^{\circ} \mathrm{C}$. (d) TGA curves, demonstrating the improvement of thermal stability of the NCO-sP(EO-stat-PO) gels with 1 wt \% laponite.

broken down and reconstituted during dynamic strains relative to those remaining intact and unchanged. The loss factors for both gel systems (i.e., with/without laponite) are respectively found to be 0.014 and 0.0058 , indicating that extensive rearrangement of highly entangled polymer material took place during strain development. ${ }^{39}$ Furthermore, the incorporation of laponites into the gelation system induced opaqueness (Figure $2 c$, inset), implying the presence of laponites as aggregate in the gel matrix. The arrangement and orientation of clays in the gel matrix were studied through wide-angle X-ray scattering (WAXS). Figure 3a displays the XRD patterns of the clays in PBS and a hydrogel matrix, which revealed a broad peak centered on $2 \theta$ of $28^{\circ}(d$-spacing $=3.18 \AA)$ attributable to a low degree of ordering of the clays in both the medium and the gel matrix. However, XRD spectrum of the laponite powder displayed sharp peaks at $20^{\circ}(d$-spacing $=4.44 \AA), 35.5^{\circ}(d$ spacing $=2.52 \AA)$, and $60^{\circ}(d$-spacing $=1.54 \AA)$.

An aqueous solution of laponite on a mica surface was analyzed by AFM, which revealed the presence of aggregates of various sizes (Figure $3 \mathrm{~b}$ ). Hence, the formation of gels can be elucidated with the following scenario. First, the laponite forms aggregates in PBS buffer. Then, the cross-linking of NCO$\mathrm{sP}(\mathrm{EO}-$ stat-PO)s occurs among the laponite aggregates, leading to an opaque hydrogel network as illustrated in the inset in Figure 3a. We also examined the effect of $\mathrm{pH}$ on laponite aggregation. DLS analyses of an aqueous laponite solution showed $\mathrm{pH}$-dependent aggregation, where acidic $\mathrm{pH}$ values favor microsized aggregates in water and PBS (Figure S2). To determine the effect of laponite on the phase behavior of the $\mathrm{sP}(\mathrm{EO}-$ stat-PO) gels, DSC analyses were carried out on the lyophilized gel samples with/without $1 \mathrm{wt} \%$ laponite. Linear PEO chains with $M_{\mathrm{n}} \geq 2 \mathrm{kDa}$ are crystalline. Dependent on the cooling rate and molecular weight of PEO, their crystallization and melting temperatures range from 55 to $40{ }^{\circ} \mathrm{C}$ and from 58 to $65{ }^{\circ} \mathrm{C}$, respectively. ${ }^{12}$ The glass transition temperature $\left(T_{\mathrm{g}}\right)$ of the amorphous part of PEGs appears at approximately -62 ${ }^{\circ} \mathrm{C}$. In contrast to $\mathrm{PEG}$, poly(EO-stat-PO) is an amorphous polymer and does not crystallize. The DSC curves of the lyophilized gels are shown in Figure $3 c$, where the $T_{g}$ of the laponite-free gel was observed at $-59.6{ }^{\circ} \mathrm{C}$ with a corresponding heat capacity $\left(\Delta C_{p}\right)$ of $0.187 \mathrm{~J} /(\mathrm{g} \cdot \mathrm{K})$ and the melting of bound water was observed at $0{ }^{\circ} \mathrm{C}( \pm 0.5)$ with a corresponding enthalpy of $0.96 \mathrm{~mW} / \mathrm{mg}$. The incorporation of laponite did not affect $T_{g}$, but it did change the cold crystallization temperature $\left(T_{c}\right)$ of the bound water. The laponite-free gel showed a $T_{\mathrm{c}}$ at $-32.3{ }^{\circ} \mathrm{C}$ with $\Delta H$ of 0.086 $\mathrm{mW} / \mathrm{mg}$. On the other hand, the gel with 1 wt \% laponite displayed a $T_{\mathrm{c}}$ at $-28.8{ }^{\circ} \mathrm{C}$ with $\Delta H$ of $0.186 \mathrm{~mW} / \mathrm{mg}$. The thermal behavior of the gels after preparation was investigated by TGA. Figure $3 \mathrm{~d}$ shows that the TGA curves of the gels displayed a significant mass loss between 50 and $175^{\circ} \mathrm{C}$, related to the loss of water molecules. In the gel with $1 \mathrm{wt} \%$ laponite, the loss of water molecules occurred at higher temperatures as a result of interactions between water and laponite particles. Due to the negative charges on the clay surface, the ionic interactions may exist between water molecules and clay, causing the adsorption of water. The water molecules in the laponite-free hydrogel release at lower temperatures. The first derivative TGA curves for both samples are shown in Figure S5, where the samples revealed two peaks: the first peak at lower temperatures is related to the water-loss, and the second one, to the pyrolysis of the polymer. The pyrolysis of the $(\mathrm{sP}$ (EO-statPO)) gels started at ca. $300{ }^{\circ} \mathrm{C}$ and ended at $425{ }^{\circ} \mathrm{C}$. The peak pyrolysis temperature shifted from 381 to $390{ }^{\circ} \mathrm{C}$ with laponite incorporation. 

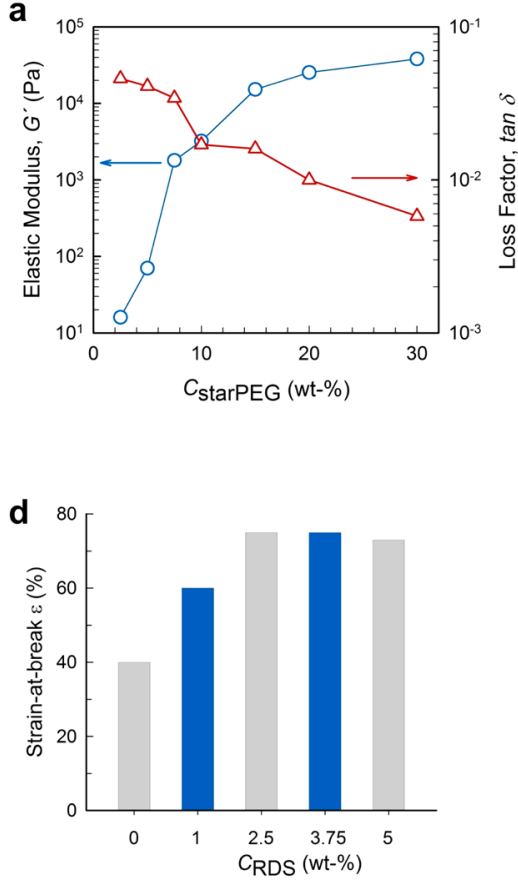
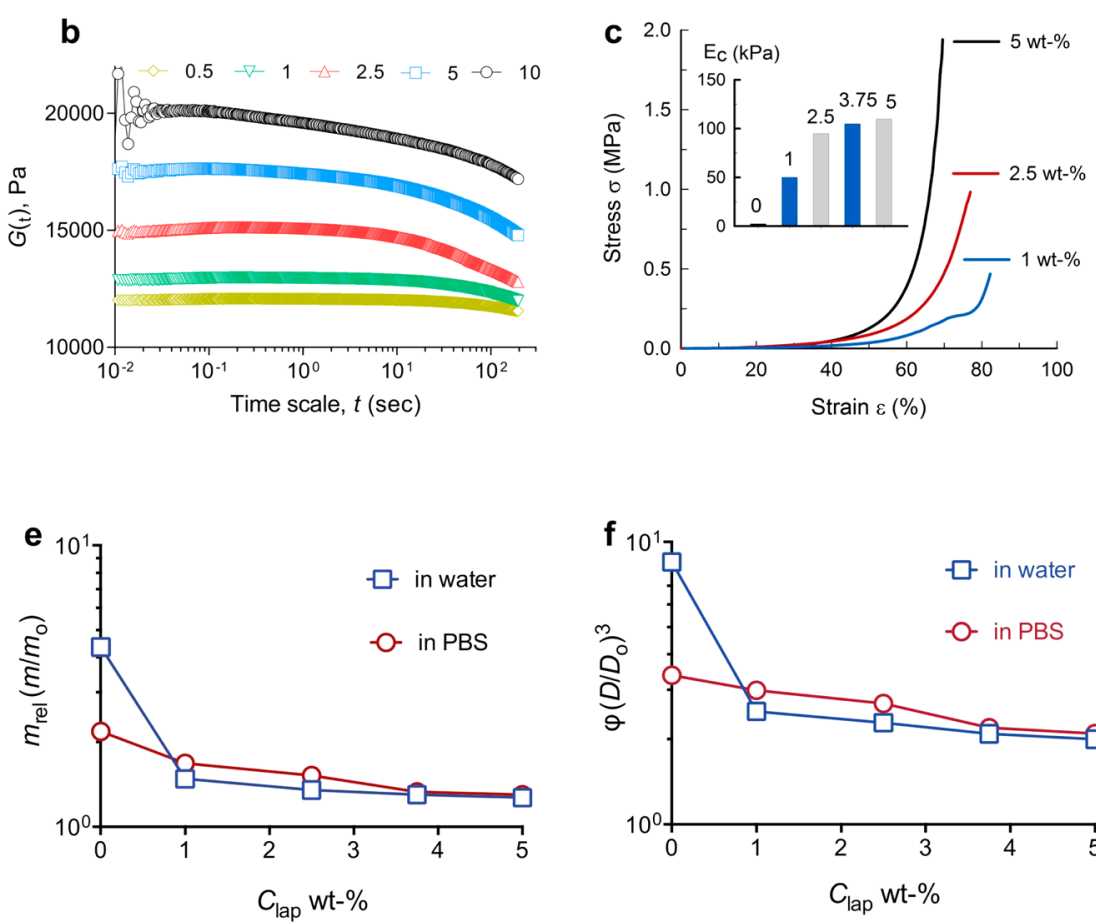

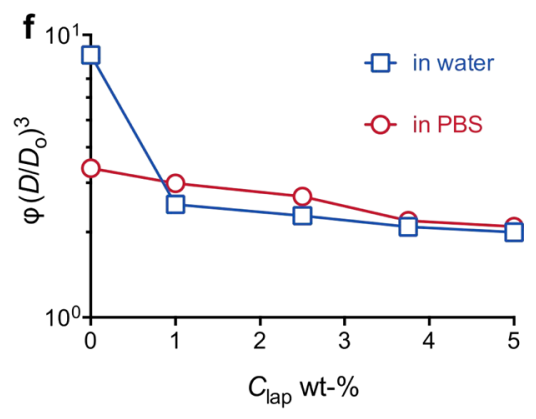

Figure 4. Mechanical and swelling properties of the nanocomposite hydrogels. (a) Variation of $G^{\prime}$ and $\tan \delta$ with $\mathrm{sP}(\mathrm{EO}-$ stat-PO) content. (b) Stress-relaxation profiles of the nanocomposite system $\left(c_{\mathrm{sP}(\mathrm{EO}-\text { stat-PO) }}=30 \mathrm{wt} \%\right.$, and $\left.c_{\text {lap }}=1 \mathrm{wt} \%\right)$. (c) Stress-strain curves and (d) strain-at-break values of the $10 \mathrm{wt} \% \mathrm{sP}(\mathrm{EO}-$ stat-PO) hydrogels with various laponite contents (between 1 and $5 \mathrm{wt} \%)$. Inset shows the compression moduli $\left(E_{\mathrm{c}}\right)$ of the gels. $(\mathrm{e}-\mathrm{f})$ Relative swelling ratios $\left(m_{\mathrm{rel}}\right.$ or $\left.\phi\right)$ of the hydrogels as a function of laponite concentration in water and PBS. The solid curves are guides to the eye.

The mechanical properties of the nanocomposite gels with 1 wt \% laponite and various $\mathrm{sP}(\mathrm{EO}-$ stat-PO) contents are shown in Figure 4a. With increasing $\mathrm{sP}(\mathrm{EO}-$ stat-PO) concentration, the elastic modulus $\left(G^{\prime}\right)$ significantly increased. For example, with an increase of prepolymer content from 10 to $30 \mathrm{wt} \%$, the elastic modulus $\left(G^{\prime}\right)$ increased 10 -fold from 3.5 to $35 \mathrm{kPa}$, while the loss factor $(\tan \delta$ ) decreased from 0.02 to 0.006 , so the network became stiffer. This stiffness can be attributed to the dominating effect of the chemically cross-linked polymer network. However, increasing the content of laponite leads to a tougher network. The stiffness and toughness of a hydrogel are often inversely related. According to the Lake-Thomas model, an increase in the cross-linking density should decrease the toughness, but it increases the stiffness. ${ }^{40,41}$ This can be explained by the prominent effect of the cross-linking of $\mathrm{sP}(\mathrm{EO}-$ stat-PO)s at high concentrations, which dominates the laponite-induced toughness of the gels. Strain-dependent properties of a nanocomposite gel were measured by stressrelaxation experiments, where the stress $\sigma\left(t, \gamma^{\circ}\right)$ was recorded after a shear deformation of a controlled amplitude $(\gamma)$ for a duration of $300 \mathrm{~s}$. Figure $4 \mathrm{~b}$ shows the relaxation profiles of the nanocomposite gel $\left(c_{\mathrm{sP}}\right.$ (EO-stat-PO) $=30 \mathrm{wt} \%$, and $\left.c_{\text {lap }}=1 \mathrm{wt} \%\right)$ at various strains, where the relaxation modulus $\left(G_{t}\right)$ is shown as a function of time $(t)$. The relaxation modulus $G(t, \gamma)$ decreased with time and became more distinctive depending on the applied initial strain level. Further, the relaxation process occurred slowly. Interestingly, when the strain $(g)$ increased over $10 \%$, all stress-relaxation profiles first showed a rapid increase in the relaxation modulus and then a decrease in this modulus (Figure S7). This is due to the fact that the measurements are no longer in the linear viscoelastic range (LVE). Similar stress-relaxation behavior was observed for the nanocomposite gel prepared at $10 \mathrm{wt} \% \mathrm{sP}(\mathrm{EO}$-stat-PO) with 1 wt \% laponite. The mechanical properties of the hydrogels were studied by DMA over the stress-strain curves (Figure 4c,d). Increasing the laponite content caused significant changes to the compression modulus $\left(E_{\mathrm{c}}\right)$ and the stress-at-break $\left(\sigma_{\mathrm{B}}\right)$. For example, for an increase in laponite content from 0 to $5 \mathrm{wt} \%$ for the gel with $10 \mathrm{wt} \% \mathrm{sP}(\mathrm{EO}-$ stat-PO), the compression moduli $\left(E_{\mathrm{c}}\right)$ of the respective hydrogels increased from 2.4 to $120 \mathrm{kPa}$. For an increase of the $\mathrm{sP}(\mathrm{EO}$-stat-PO) concentration from 10 to $30 \mathrm{wt} \%$, the respective compression modulus of the gel with 1 wt \% laponite increased from 50 to $970 \mathrm{kPa}$, obviously suggesting the mechanical improvement of the gels with laponite incorporation (Figure S6). These marked changes were also observed in the strain-at-break values $\left(\varepsilon_{\mathrm{B}}\right)$ of the hydrogels with incorporation of laponite (Figure $4 \mathrm{~d}$ ). The swelling properties of the hydrogels were investigated in water and PBS. Figure $4 \mathrm{e}, \mathrm{f}$ shows equilibrium swelling ratios $\left(m_{\mathrm{rel}}\right.$ and $\phi)$ of the hydrogels with various laponite content. Since the laponite clays act as additional cross-linking domains, the swelling ratios $\left(m_{\text {rel }}\right.$ and $\left.\phi\right)$ decrease with increasing laponite content.

Figure 5 shows the inner structures of the lyophilized gels. High-resolution SEM analysis revealed that the $\mathrm{S}(\mathrm{EO}-$-stat-PO) hydrogel is homogeneous, whereas the nanocomposite gel showed a heterogeneous matrix with embedded clay aggregates. Additionally, the presence of laponites was confirmed by EDX, where the spectrum showed peaks for $\mathrm{Si}$ (silicon) and $\mathrm{Mg}$ (magnesium) (Figure 5). This proves the presence of embedded clays into the matrix, whereas the hydrogel prepared without clays showed no peaks for these elements.

Functional Scaffolds for Drug Delivery. These nanocomposite hydrogels were uniquely functionalized with $\mathrm{BCN}$ motifs for the release of chemically bound molecules. BCN motifs are cyclic functional molecules with a nonbenzoannu- 

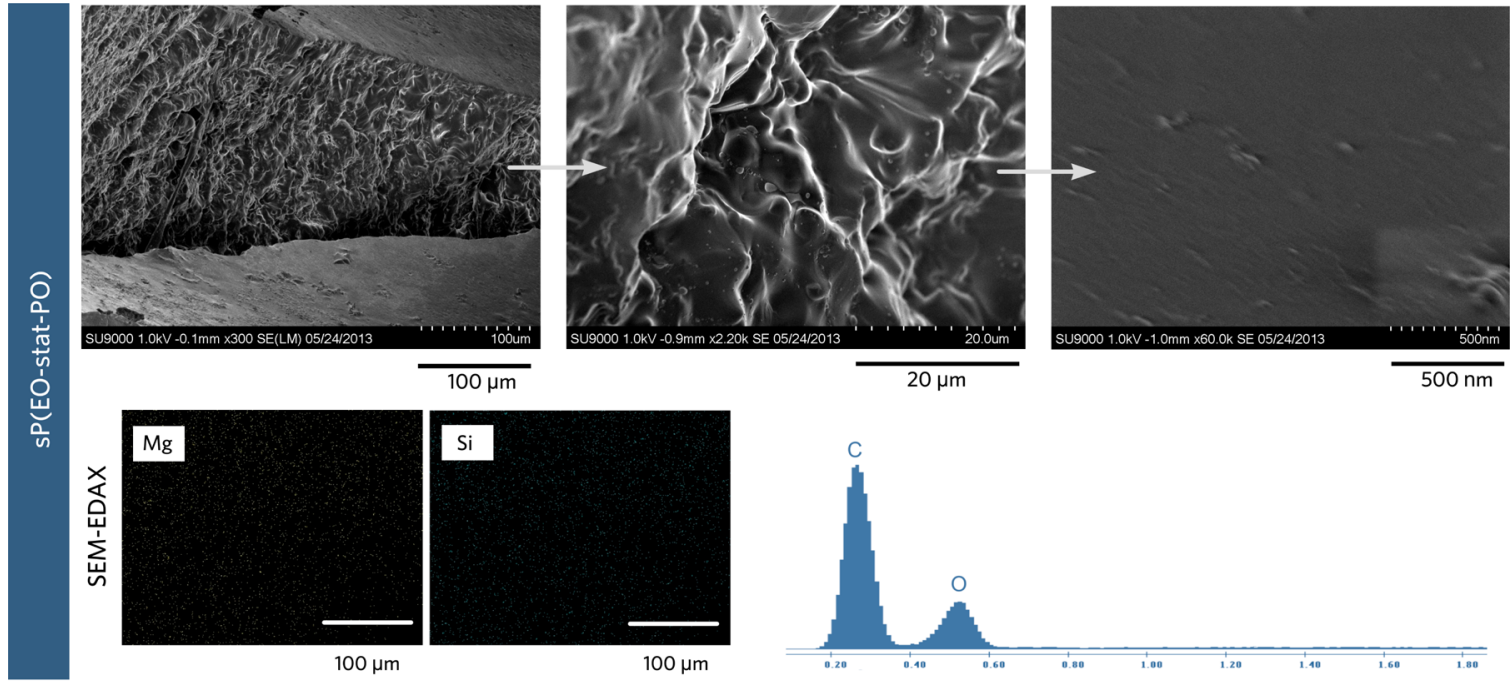

$20 \mu \mathrm{m}$

$500 \mathrm{~nm}$
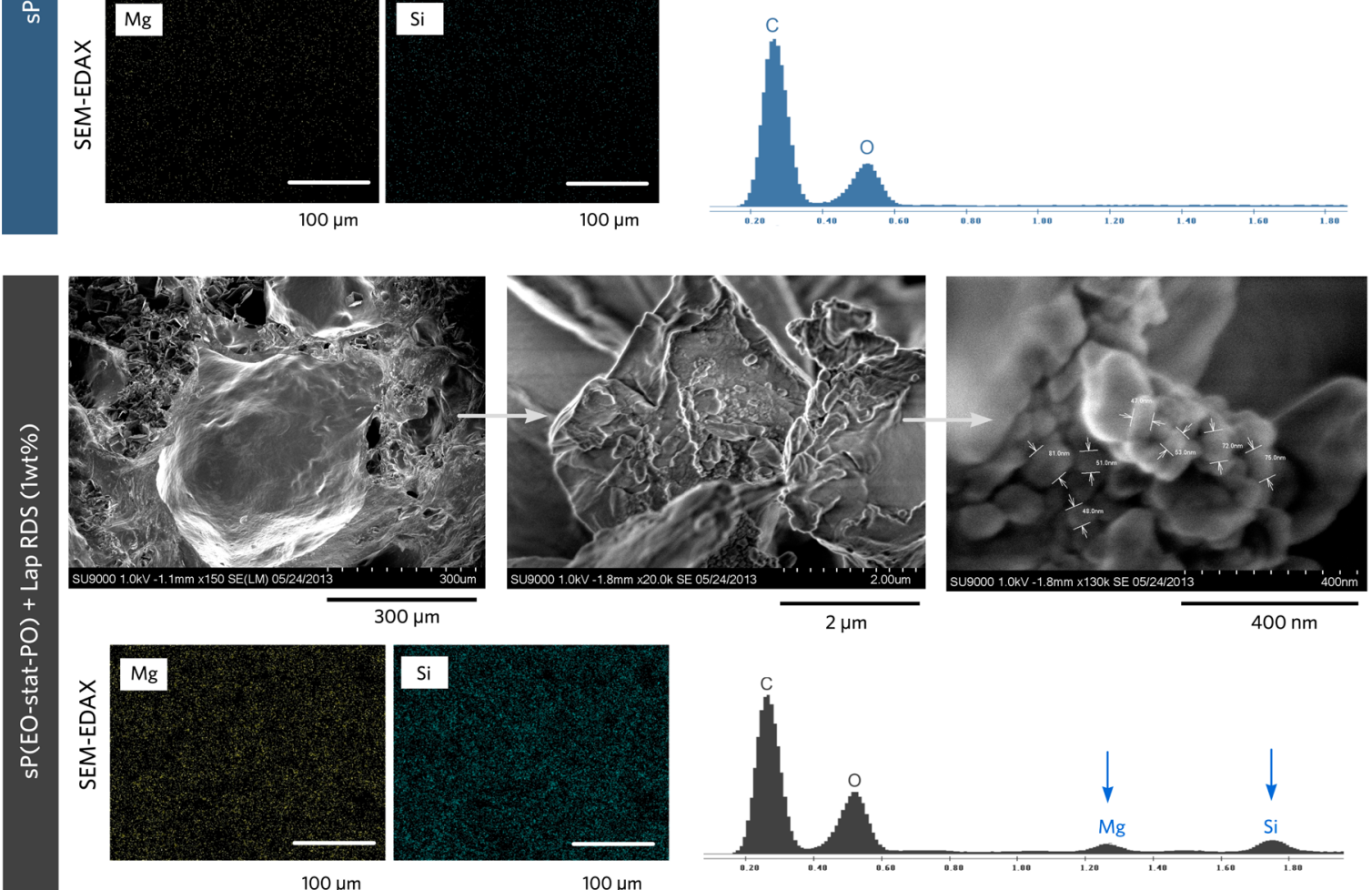

Figure 5. $\mathrm{SEM}$ images and $\mathrm{EDX}$ analyses of the lyophilized $\mathrm{sP}(\mathrm{EO}-$ stat- $\mathrm{PO})$ and $\mathrm{sP}\left(\mathrm{EO}-\right.$-stat-PO)-laponite gels $\left(c_{\mathrm{sP}(\mathrm{EO}-\text {-stat-PO })}=10\right.$ wt $\%$, and $c_{\text {lap }}=1$ wt \%).

lated cyclooctyne ring, which reacts bioorthogonally with azides through a strain-promoted alkyne-azide reaction (SPAAC), yielding a triazole ring. The reaction does not require any metal catalyst and has also been used in a biological milieu without any toxicity. Furthermore, the triazole ring is resistant to hydrolysis, reduction, oxidation, or other types of cleavage. A wide range of $\mathrm{BCN}$ molecules having various functionalities are already available in the market, and the reaction rates of these molecules vary in the range of $2 \times 10^{-3}$ to $1.16 \mathrm{M}^{-1} \mathrm{~s}^{-1}$ depending on the groups substituted on the cyclooctyne ring, such as electron-withdrawing groups, fluorine, and azidefunctional molecules; e.g., BCNs react much faster with electron-deficient aryl azides than aliphatic azides. ${ }^{42}$

Figure 6a displays the nanocomposite hydrogels, which were produced with/without azide dye, under fluorescence light. The azide dye attached to the scaffold induces fluorescence, whereas the gel without dye displays no fluorescence. The timedependent release behavior from the hydrogel matrix was monitored with a fluorescence spectrophotometer, and the data were later transformed into the percent (\%) release using the control solutions of the dye. Figure $6 \mathrm{~b}$ shows the initial release of the unbound dye as first, followed by the release of covalently bound dye from the matrix, which occurs slowly but much faster than the degradation of the hydrogel. One can suppose that the decomposition process of the large triazole moieties turns the fluorescence off, which would most likely deactivate them. However, triazoles are relatively stable rings and do not easily destabilize without certain conditions.

Carbamates are chemical groups that have carbonyl groups linked to oxygen and nitrogen on both sides. There exists more than one bond whose fission can lead to the deprotection of the amine (Figure $6 \mathrm{c}$ ). Fissions $\mathrm{B}$ and $\mathrm{C}$ are less probable due to the low reactivity of the urethane carbonyl to nucleophiles. ${ }^{43}$ On the other hand, fission A (alkyl-oxygen fission) is the most probable pathway leading to the deprotection of the urethaneprotected amine. The carbamate bond decomposes to the amine, liberating $\mathrm{CO}_{2}$, unlike ester cross-linked networks, which are mostly based on lactic or glycolic acids and produce acids upon hydrolysis. The nanocomposite hydrogels were slowly degraded in PBS (Figure 6d). Zhang et al. reported the degradation of the polymer hydrogel based on lysine diisocyanate (LDI) and glucose. ${ }^{44}$ The degradation was due to the hydrolysis of carbamate bonds and varied from a couple of weeks to several months depending on the incubation 
a

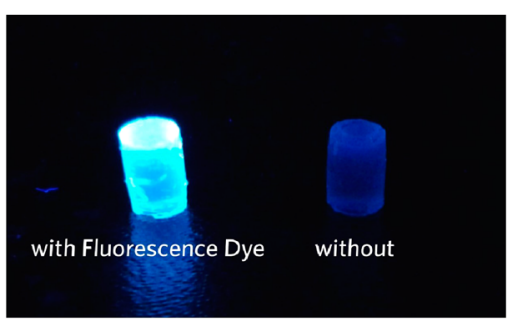

Nanocomposite gels

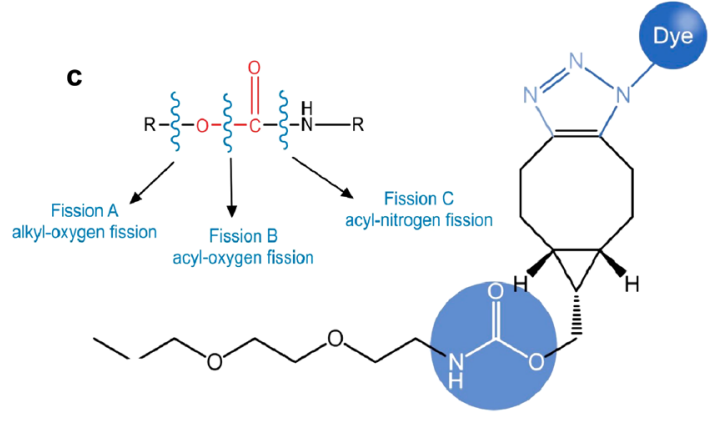

Degradable carbamate link
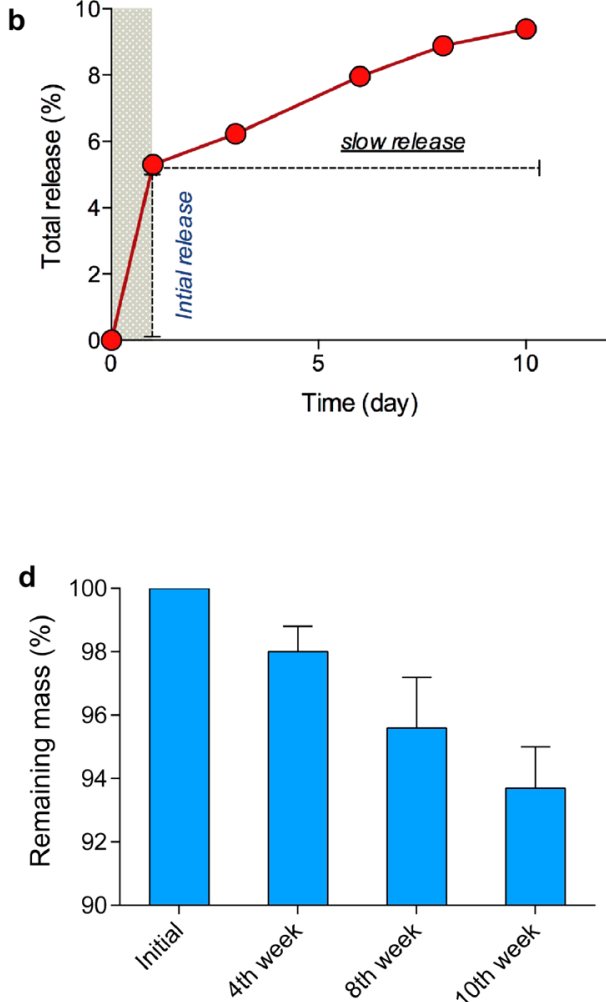

Figure 6. Hydrogel degradation and release kinetics of a fluorescence dye. (a) Photo of the gels under fluorescence light and (b) time-dependent

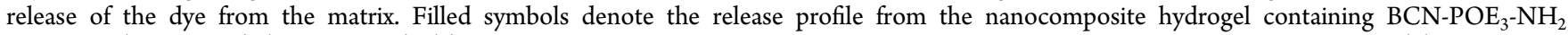
molecules $(0.22 \mathrm{mmol})\left(c_{\text {lap }}=1 \mathrm{wt} \%\right)$. (c) Chemical structure of BCN after clicking with the azide-functional fluorescence dye and (d) degradation profile of the nanocomposite hydrogels over time.

temperature; i.e., the hydrogels degraded at $65 \%$ in 2 months at $37{ }^{\circ} \mathrm{C}$, whereas the same hydrogel degraded less than $5 \%$ at 4 ${ }^{\circ} \mathrm{C}$. This also supports our finding, which shows the release of less than $6 \%$ of the bound dye from the gel matrix in 10 days due to gradual network degradation.

Fabrication of Ultrathin Nanocomposite Gel Coatings. One major problem with nanocomposite systems is their suitability for coating applications, particularly in medical implants. Principally, this is important to benefit from the mechanical and cell binding features of the nanocomposite gels. It is expected that the incorporation of the clays leads to stiffer and mechanically durable nanocomposite gel coatings. In this regard, the presented nanocomposite system can be an ideal solution since it possesses the in situ network-forming property of multifunctional isocyanate end-capped star PEG molecules. On exposure of the NCO-sP(EO-stat-PO)s to an amino functional surface, the terminal $\mathrm{NCO}$ groups react with surface amines. The residual isocyanates partially hydrolyze into amino groups and react with the remaining NCO groups so that ultrathin hydrogel films can be produced. For this reason, the aminosilylated substrates were treated with precursors (NCO$\mathrm{sP}(\mathrm{EO}$-stat-PO), $\mathrm{BCN}$, and laponite) and incubated overnight to ensure complete cross-linking of the components. For the preparation of nanocomposite coatings, water was used as the solvent instead of PBS to avoid possible aggregation of laponite in the coating. After the incubation, the coated substrates were rinsed with water to remove unbound components and subsequently dried under a stream of nitrogen.

The successful fabrication of the nanocomposite coating was confirmed by AFM analyses, which revealed the enhanced surface roughness with increasing laponite content (Figure
$7 \mathrm{a}, \mathrm{c})$. Additionally, the wettability of the coating was related to the amount of laponite incorporated (Figure $7 \mathrm{c}$ ). The coating prepared with $0.25 \mathrm{wt} \%$ laponite was more hydrophilic and had a contact angle of $33^{\circ}$, and the coating prepared with 0.5 wt \% laponite had a contact angle of $40^{\circ}$. The higher contact angle could be attributed to higher roughness values (Figure 7c). Layer thicknesses were calculated as $20-25 \mathrm{~nm}$ over the AFM topology profiles using Gwyddion Analysis software (ver. 2.44). The quantitative elemental composition of the nanocomposite surface coatings was determined by XPS analyses (Figure $7 \mathrm{~d}$ ). The nanocomposite layers (samples 1 and 2) showed a significant carbon peak (C) relative to the amino-functional layer (sample AS). On the other hand, the silicone peak ( $\mathrm{Si}$ ) became smaller after forming the nanocomposite coating because of the $\mathrm{sP}(\mathrm{EO}$-stat-PO) molecules. The $\mathrm{Mg} \mathrm{KLL}$ Auger peak appeared at $305 \mathrm{eV}$ for the nanocomposite coatings and increased with clay content (Figure $7 \mathrm{~d}$, inset). The quantitative elemental composition of the layers was calculated, and the results are presented in Table S1. With an increasing amount of laponite incorporated into the coatings, the $\mathrm{C}$ and $\mathrm{N}$ content decreased and the $\mathrm{Si}$ and $\mathrm{O}$ content increased, in line with the AFM images (Figure 7a).

Biocompatibility of Multifunctional Nanocomposite Gels. An efficient biomaterial for tissue engineering applications should be partially designed on the basis of its influence on the reaction of inflammatory cells because this is a crucial parameter for biocompatibility. ${ }^{45}$ Dependent on the behavior of macrophages, polymeric implants have recently been optimized for soft tissue regeneration, specifically blood vessels and heart muscles. ${ }^{46}$ In addition to the material itself, components of the material should be biocompatible. In this context, isocyanates 
(a)
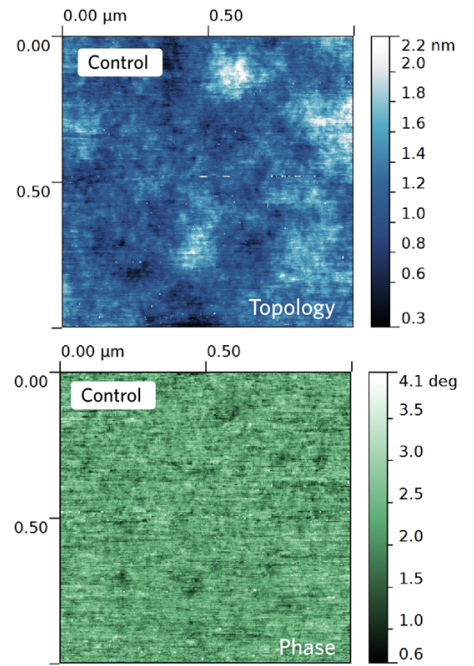

(b)

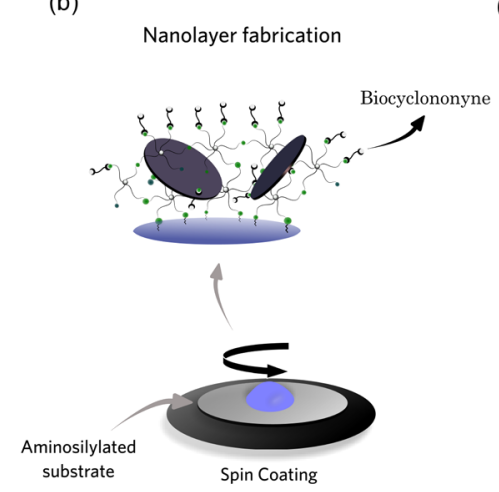

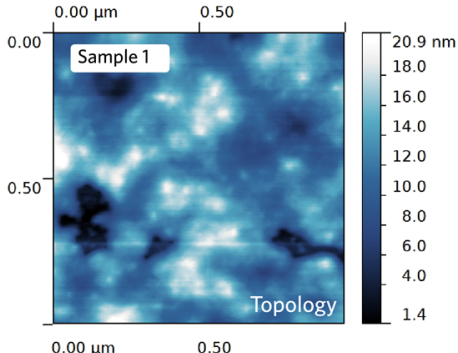
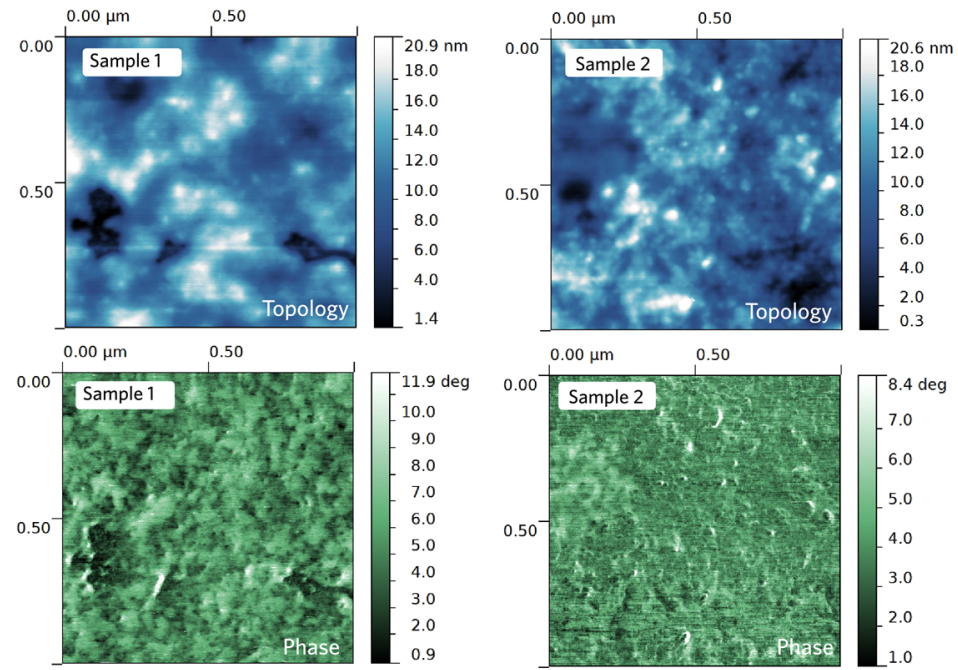

(c)
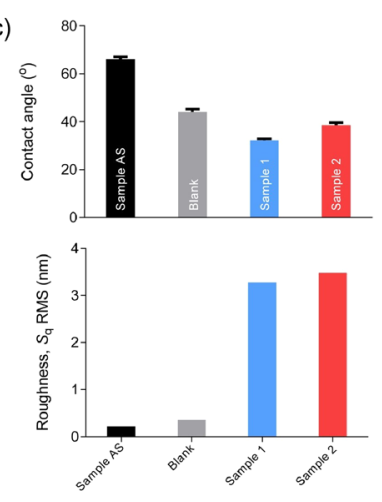

(d)

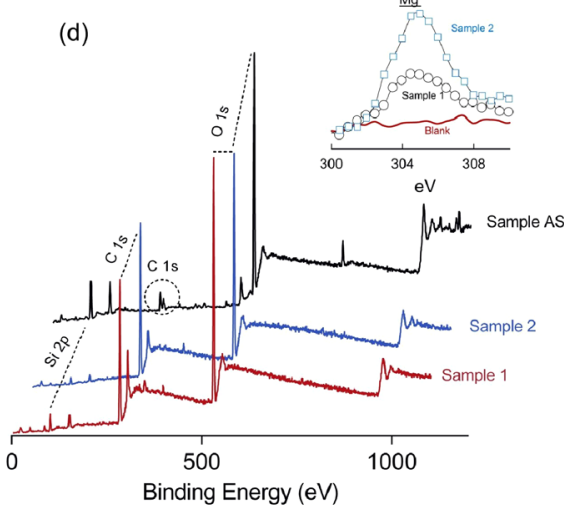

Figure 7. Characterization of the ultrathin nanocomposite layers. (a) Topological and phase images of the nanocomposite coatings by AFM. (b) Cartoon illustration of the fabrication of ultrathin nanocomposite coatings. (c) Roughness values and contact angles of the coatings. The RMS roughness values $\left(S_{\mathrm{q}}\right)$ were calculated over the projected area of $1 \mu \mathrm{m}^{2}$. Blank stands for the sample prepared without clay, and AS stands for the aminosilylated surface. (d) XPS spectra of the coatings. Inset shows Mg KLL narrow scan XPS spectra of the coatings. The clay contents in samples 1 and 2 are 2.5 and $5 \mathrm{mg} / \mathrm{mL}$, respectively.

(NCO) and their bioapplications are important due to their toxicity, since other ingredients of the presented system (sP(EO-stat-PO), BCN, and laponite) are known to be biocompatible. $^{20,47,48}$

Isocyanate $(\mathrm{NCO})$ groups strongly react with amines $\left(\mathrm{NH}_{2}\right)$ and even with hydroxyl groups $(\mathrm{OH})$ at physiological $\mathrm{pH}$ and are commonly known to negatively interfere with cellular functions and development. ${ }^{49}$ However, most of the isocyanates used are hydrophobic molecules with a low molecular weight. In contrast, we used PEG-based macromers with terminal NCO groups, which make up less than $3 \%$ of the whole molecule. Additionally, NCO groups hydrolyze into biocompatible amine groups $\left(\mathrm{NH}_{2}\right)$ in aqueous solutions in less than $1 \mathrm{~h}$ (Figure 8ii). Upon the completion of hydrolysis, the system becomes biocompatible, and there will be no free reactive NCO groups available for uncontrolled reactions. ${ }^{48}$ This is in line with the results of Lendlein and colleagues on the one-step fabrication of multifunctional hydrogels using L-lysine diisocyanate ethyl ester (LDI) with gelatin for bone regeneration, where no significant toxicity of the scaffolds induced by diisocyanate linkers in vivo and in vitro was observed. ${ }^{50}$

To study cell viability on three-dimensional materials by optical microscopy, we used fluorescent macrophages. The fluorescence of the cells correlated with their viability, meaning that the green fluorescent cells on the control material (Figure $8 \mathrm{~A}-\mathrm{D}$ ) and representative hydrogel (Figure $8 \mathrm{E}-\mathrm{H}$ ) were viable. In contrast, dead cells lost their green fluorescence on a toxic material and exhibited a red signal after propidium iodide staining (Figure 8I-L). To study the effects of the properties of these materials on cell viability, we cultured fluorescent macrophages on these materials. We studied cell behavior after $2 \mathrm{~h}$ of culture to evaluate the attachment of macrophages on materials coated with the NCO-sP(EO-stat-PO) hydrogel, which are known to be cell-repulsive. ${ }^{51}$ The fluorescence of the cells on the laponite-based materials was very intense. The initial attachment of macrophages to hydrogels with a laponite content of $0.5 \%$ was low, and the cells also exhibited a lower intensity of fluorescence compared to that on the hydrogel containing 1 wt \% laponite. After 48 h of culture, macrophages had proliferated on the material (Figure 8i), suggesting the biocompatibility of the laponites. Likewise, Gaharwar et al. showed that increasing the laponite content induced higher cell proliferation. ${ }^{52}$ Given the gelation time, we conclude that the hydrogel having $1 \mathrm{wt} \%$ laponite might assist tissue regeneration in vivo after injection by increasing the cell number and might assist in healing injured tissues upon injection. In such a case, the possible toxicity of free isocyanate groups on cell viability is probably minimized by the laponite clays because of the proliferation of cells (Figure 8iii). 
(i)
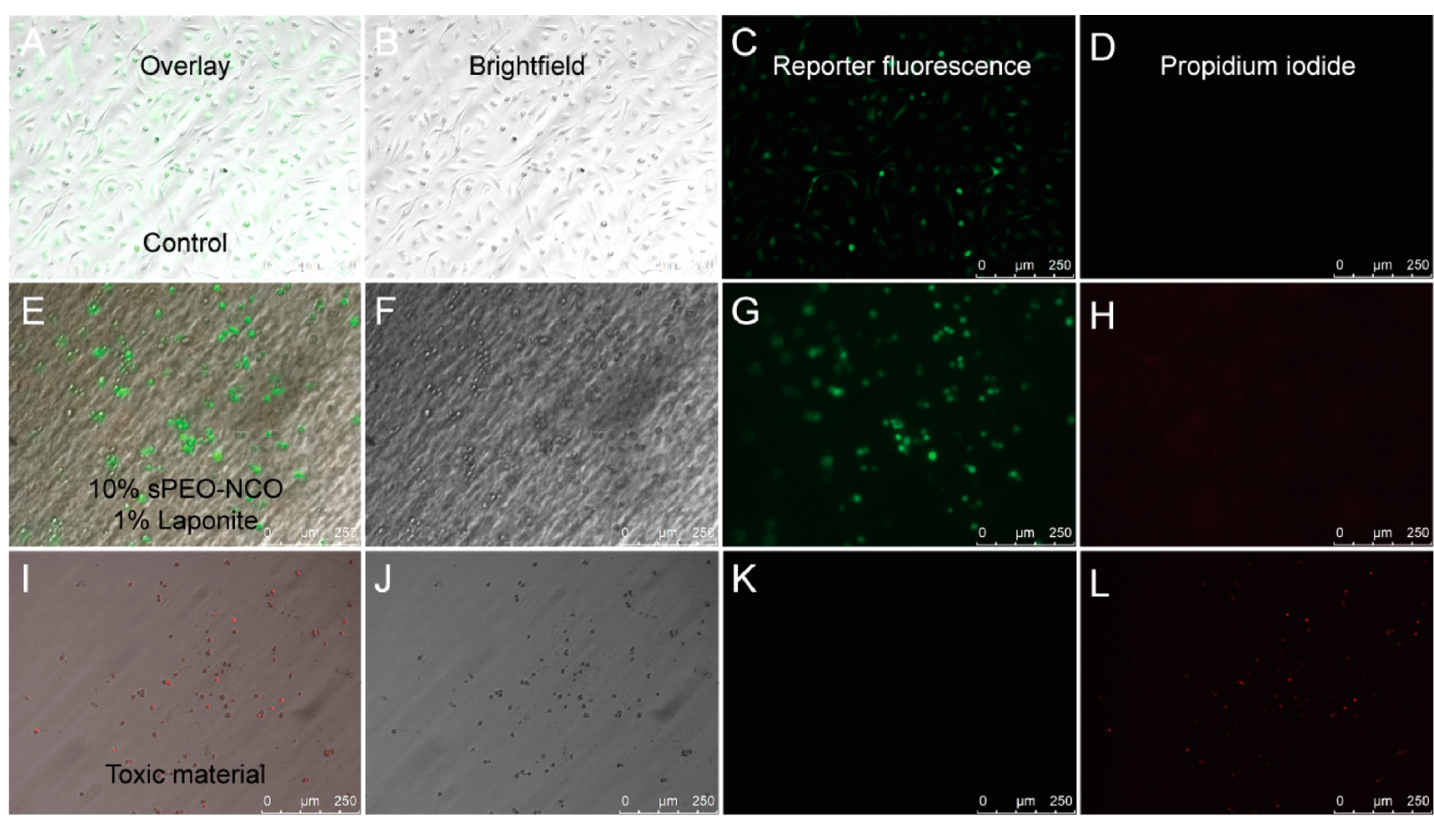

(ii)

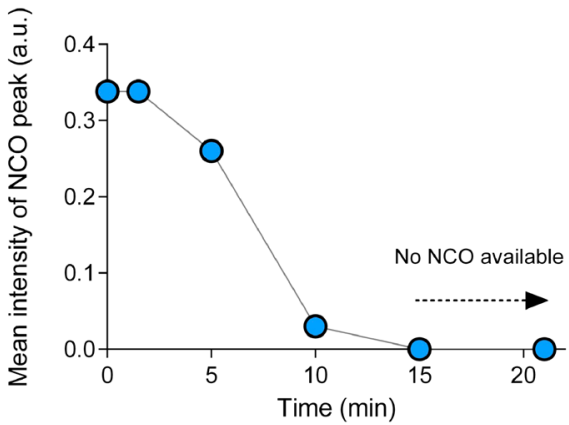

(iii)

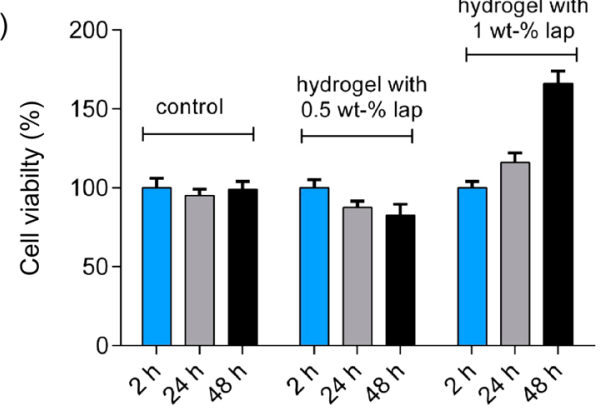

Cell culture period (hours)

Figure 8. Cellular fluorescence as a reporter of viability. (i) Fluorescent murine macrophages were cultured on different materials to demonstrate the function of the cellular green fluorescence protein as a viability reporter. Macrophages were cultured for $48 \mathrm{~h}$ on tissue culture treated polystyrol (A$\mathrm{D})$, on a representative material, a hydrogel consisting of $10 \% \mathrm{sP}(\mathrm{EO}-$ stat-PO) $(\mathrm{E}-\mathrm{H})$, and on a toxic hydrogel material (I-L). Propidium iodide staining was performed to determine cell viability. (ii) Mean intensity of the NCO peak as a function of time at $c_{\mathrm{sP}(\mathrm{EO}-\text {-stat-PO) }}=50 \mathrm{wt} \%$ in PBS. (iii) Variation in cell viability (percentage) as a function of time for the nanocomposite gels with different laponite concentrations.

\section{CONCLUSIONS}

We present here a novel and versatile nanocomposite system which possesses many desirable gel characteristics, such as injectability, high mechanical strength, degradability, biocompatibility, BCN functionality, and suitability for nanolayer coatings. The mechanically strong hydrogels $\left(E_{\mathrm{c}} \sim 1 \mathrm{MPa}\right)$ were synthesized by the in situ rapid gelation of NCOterminated PEG-based macromers in the presence of laponite clays. The network characteristics were examined by several techniques such as rheology, DMA, WAXS, SEM, AFM, TGA, DSC, DLS, and contact angle analyses. Cell viability was studied using murine macrophages and showed the biocompatibility of the gel system: The cell number increased with laponite content. Covalently bound $\mathrm{BCN}$ motifs were used to ligate azide functional molecules, and their gradual release from the matrix was recorded. Furthermore, this gelation system was employed to produce ultrathin hydrogel coatings with thicknesses below $100 \mathrm{~nm}$ and tunable wettability. With this facile and versatile approach, nanocomposite gels can be either fabricated as bulk hydrogels or spin-coated to obtain ultrathin films with desired functional motifs.

\section{ASSOCIATED CONTENT}

S Supporting Information

. The Supporting Information is available free of charge on the ACS Publications website at DOI: 10.1021/acs.biomac.6b01483.

Results of the rheological, DLS, TGA, DMA, and XPS analyses of nanocomposite gels as well as DLS analysis of laponite (PDF)

\section{AUTHOR INFORMATION}

\section{Corresponding Author}

*E-mail: fuat.topuz@rwth-aachen.de.

\section{ORCID}

Fuat Topuz: 0000-0002-9011-4495

\section{Author Contributions}

F.T. designed and conceived the experiments. The experiments were performed by F.T., M.B., and Y.P.

Notes

The authors declare no competing financial interest. 


\section{ACKNOWLEDGMENTS}

F.T. gratefully acknowledges continuous support by Martin Moeller.

\section{ABBREVIATIONS}

$\mathrm{sP}(\mathrm{EO}$-stat-PO), star-type poly(ethylene oxide-stat-propylene oxide); $\mathrm{NCO}$, isocyanate; $\mathrm{BCN}$, bicyclononyne

\section{REFERENCES}

(1) Topuz, F.; Buenger, D.; Tanaka, D.; Groll, J. Hydrogels in Biosensing Applications A2. In Comprehensive Biomaterials; Ducheyne, P., Ed.; Elsevier: Oxford, 2011; pp 491-517.

(2) Buenger, D.; Topuz, F.; Groll, J. Hydrogels in sensing applications. Prog. Polym. Sci. 2012, 37 (12), 1678-1719.

(3) Li, Y.; Rodrigues, J.; Tomas, H. Injectable and biodegradable hydrogels: gelation, biodegradation and biomedical applications. Chem. Soc. Rev. 2012, 41 (6), 2193-2221.

(4) Vermonden, T.; Censi, R.; Hennink, W. E. Hydrogels for Protein Delivery. Chem. Rev. 2012, 112 (5), 2853-2888.

(5) Seliktar, D. Designing Cell-Compatible Hydrogels for Biomedical Applications. Science 2012, 336 (6085), 1124-1128.

(6) Sharifi, S.; Blanquer, S. B. G.; van Kooten, T. G.; Grijpma, D. W. Biodegradable nanocomposite hydrogel structures with enhanced mechanical properties prepared by photo-crosslinking solutions of poly(trimethylene carbonate)-poly(ethylene glycol)-poly(trimethylene carbonate) macromonomers and nanoclay particles. Acta Biomater. 2012, 8 (12), 4233-4243.

(7) Deng, G.; Tang, C.; Li, F.; Jiang, H.; Chen, Y. Covalent CrossLinked Polymer Gels with Reversible Sol-Gel Transition and SelfHealing Properties. Macromolecules 2010, 43 (3), 1191-1194.

(8) Cordier, P.; Tournilhac, F.; Soulie-Ziakovic, C.; Leibler, L. Selfhealing and thermoreversible rubber from supramolecular assembly. Nature 2008, 451 (7181), 977-980.

(9) Tuncaboylu, D. C.; Sari, M.; Oppermann, W.; Okay, O. Tough and Self-Healing Hydrogels Formed via Hydrophobic Interactions. Macromolecules 2011, 44 (12), 4997-5005.

(10) Liu, J.; Chen, C.; He, C.; Zhao, J.; Yang, X.; Wang, H. Synthesis of Graphene Peroxide and Its Application in Fabricating Super Extensible and Highly Resilient Nanocomposite Hydrogels. ACS Nano 2012, 6 (9), 8194-8202.

(11) Banik, S. J.; Fernandes, N. J.; Thomas, P. C.; Raghavan, S. R. A New Approach for Creating Polymer Hydrogels with Regions of Distinct Chemical, Mechanical, and Optical Properties. Macromolecules 2012, 45 (14), 5712-5717.

(12) Dalton, P. D.; Hostert, C.; Albrecht, K.; Moeller, M.; Groll, J. Structure and Properties of Urea-Crosslinked Star Poly[(ethylene oxide)-ran-(propylene oxide)] Hydrogels. Macromol. Biosci. 2008, 8 (10), 923-931.

(13) Na, Y. H. Double network hydrogels with extremely high toughness and their applications. Korea-Australia Rheology Journal 2013, 25 (4), 185-196.

(14) Hao, J.; Weiss, R. A. Viscoelastic and Mechanical Behavior of Hydrophobically Modified Hydrogels. Macromolecules 2011, 44 (23), 9390-9398.

(15) Karpovich, A. L.; Vlasova, M. F.; Sapronova, N. I.; Sukharev, V. S.; Ivanov, V. V. Determination of dimensions of exfoliating materials in aqueous suspensions. MethodsX 2016, 3, 19-24.

(16) Negrete-Herrera, N.; Putaux, J.-L.; Bourgeat-Lami, E. Synthesis of polymer/Laponite nanocomposite latex particles via emulsion polymerization using silylated and cation-exchanged Laponite clay platelets. Prog. Solid State Chem. 2006, 34 (2-4), 121-137.

(17) Gaharwar, A. K.; Kishore, V.; Rivera, C.; Bullock, W.; Wu, C.-J.; Akkus, O.; Schmidt, G. Physically Crosslinked Nanocomposites from Silicate-Crosslinked PEO: Mechanical Properties and Osteogenic Differentiation of Human Mesenchymal Stem Cells. Macromol. Biosci. 2012, 12 (6), 779-793.

(18) Jugdaohsingh, R. Silicone and bone health. J. Nutr. Health Aging 2007, 11 (2), 99-110.
(19) Jurkić, L. M.; Cepanec, I.; Pavelić, S. K.; Pavelić, K. Biological and therapeutic effects of ortho-silicic acid and some ortho-silicic acidreleasing compounds: New perspectives for therapy. Nutr. Metab. 2013, 10 (1), 2.

(20) Gaharwar, A. K.; Mihaila, S. M.; Swami, A.; Patel, A.; Sant, S.; Reis, R. L.; Marques, A. P.; Gomes, M. E.; Khademhosseini, A. Bioactive Silicate Nanoplatelets for Osteogenic Differentiation of Human Mesenchymal Stem Cells. Adv. Mater. 2013, 25 (24), 33293336.

(21) Gaharwar, A. K.; Avery, R. K.; Assmann, A.; Paul, A.; McKinley, G. H.; Khademhosseini, A.; Olsen, B. D. Shear-Thinning Nanocomposite Hydrogels for the Treatment of Hemorrhage. ACS Nano 2014, 8 (10), 9833-9842.

(22) Tamesue, S.; Ohtani, M.; Yamada, K.; Ishida, Y.; Spruell, J. M.; Lynd, N. A.; Hawker, C. J.; Aida, T. Linear versus Dendritic Molecular Binders for Hydrogel Network Formation with Clay Nanosheets: Studies with ABA Triblock Copolyethers Carrying Guanidinium Ion Pendants. J. Am. Chem. Soc. 2013, 135 (41), 15650-15655.

(23) Wang, Q.; Mynar, J. L.; Yoshida, M.; Lee, E.; Lee, M.; Okuro, K.; Kinbara, K.; Aida, T. High-water-content mouldable hydrogels by mixing clay and a dendritic molecular binder. Nature 2010, 463 (7279), 339-343.

(24) Lee, S.; Kim, H. J.; Chang, S. H.; Lee, J. Anisometric nanocomposite hydrogels with temperature responsive compartments. Soft Matter 2013, 9 (2), 472-479.

(25) Wang, M.; Yuan, D.; Fan, X.; Sahoo, N. G.; He, C. Polymer Nanocomposite Hydrogels Exhibiting Both Dynamic Restructuring and Unusual Adhesive Properties. Langmuir 2013, 29 (23), 70877095.

(26) Kochumalayil, J. J.; Morimune, S.; Nishino, T.; Ikkala, O.; Walther, A.; Berglund, L. A. Nacre-Mimetic Clay/Xyloglucan Bionanocomposites: A Chemical Modification Route for Hygromechanical Performance at High Humidity. Biomacromolecules 2013, 14 (11), 3842-3849.

(27) Gaharwar, A. K.; Peppas, N. A.; Khademhosseini, A. Nanocomposite hydrogels for biomedical applications. Biotechnol. Bioeng. 2014, 111 (3), 441-453.

(28) Baumann, M. D.; Kang, C. E.; Tator, C. H.; Shoichet, M. S. Intrathecal delivery of a polymeric nanocomposite hydrogel after spinal cord injury. Biomaterials 2010, 31 (30), 7631-7639.

(29) Appel, E. A.; Tibbitt, M. W.; Webber, M. J.; Mattix, B. A.; Veiseh, O.; Langer, R. Self-assembled hydrogels utilizing polymernanoparticle interactions. Nat. Commun. 2015, 6 (9), 6295.

(30) Kim, Y. S.; Liu, M.; Ishida, Y.; Ebina, Y.; Osada, M.; Sasaki, T.; Hikima, T.; Takata, M.; Aida, T. Thermoresponsive actuation enabled by permittivity switching in an electrostatically anisotropic hydrogel. Nat. Mater. 2015, 14 (10), 1002-1007.

(31) Liu, M. J.; Ishida, Y.; Ebina, Y.; Sasaki, T.; Aida, T. Photolatently modulable hydrogels using unilamellar titania nanosheets as photocatalytic crosslinkers. Nat. Commun. 2013, 4, 2029.

(32) Haraguchi, K.; Murata, K.; Takehisa, T. Stimuli-Responsive Nanocomposite Gels and Soft Nanocomposites Consisting of Inorganic Clays and Copolymers with Different Chemical Affinities. Macromolecules 2012, 45 (1), 385-391.

(33) Annaka, M.; Mortensen, K.; Matsuura, T.; Ito, M.; Nochioka, K.; Ogata, N. Organic-inorganic nanocomposite gels as an in situ gelation biomaterial for injectable accommodative intraocular lens. Soft Matter 2012, 8 (27), 7185-7196.

(34) García-Astrain, C.; Chen, C.; Burón, M.; Palomares, T.; Eceiza, A.; Fruk, L.; Corcuera, M. Á.; Gabilondo, N. Biocompatible Hydrogel Nanocomposite with Covalently Embedded Silver Nanoparticles. Biomacromolecules 2015, 16 (4), 1301-1310.

(35) Merino, S.; Martín, C.; Kostarelos, K.; Prato, M.; Vázquez, E. Nanocomposite Hydrogels: 3D Polymer-Nanoparticle Synergies for On-Demand Drug Delivery. ACS Nano 2015, 9 (5), 4686-4697.

(36) Yang, J.; Liu, S.; Xiao, Y.; Gao, G.; Sun, Y.; Guo, Q.; Wu, J.; Fu, J. Multi-responsive nanocomposite hydrogels with high strength and toughness. J. Mater. Chem. B 2016, 4 (9), 1733-1739. 
(37) Götz, H.; Beginn, U.; Bartelink, C. F.; Grünbauer, H. J. M.; Möller, M. Preparation of Isophorone Diisocyanate Terminated Star Polyethers. Macromol. Mater. Eng. 2002, 287 (4), 223-230.

(38) Nie, J.; Du, B.; Oppermann, W. Swelling, Elasticity, and Spatial Inhomogeneity of Poly(N-isopropylacrylamide)/Clay Nanocomposite Hydrogels. Macromolecules 2005, 38 (13), 5729-5736.

(39) Okay, O.; Oppermann, W. Polyacrylamide-Clay Nanocomposite Hydrogels: Rheological and Light Scattering Characterization. Macromolecules 2007, 40 (9), 3378-3387.

(40) Li, J.; Illeperuma, W. R. K.; Suo, Z.; Vlassak, J. J. Hybrid Hydrogels with Extremely High Stiffness and Toughness. ACS Macro Lett. 2014, 3 (6), 520-523.

(41) Lake, G. J.; Thomas, A. G. The Strength of Highly Elastic Materials. Proc. R. Soc. London, Ser. A 1967, 300 (1460), 108-119.

(42) Dommerholt, J.; Schmidt, S.; Temming, R.; Hendriks, L. J. A.; Rutjes, F. P. J. T.; van Hest, J. C. M.; Lefeber, D. J.; Friedl, P.; van Delft, F. L. Readily Accessible Bicyclononynes for Bioorthogonal Labeling and Three-Dimensional Imaging of Living Cells. Angew. Chem., Int. Ed. 2010, 49 (49), 9422-9425.

(43) Sureshbabu, V. V.; Narendra, N. Protection Reactions. In Amino Acids, Peptides and Proteins in Organic Chemistry; Wiley-VCH Verlag GmbH \& Co. KGaA: Weinheim, 2011; pp 1-97.

(44) Zhang, J. Y.; Beckman, E. J.; Hu, J.; Yang, G. G.; Agarwal, S.; Hollinger, J. O. Synthesis, biodegradability, and biocompatibility of lysine diisocyanate-glucose polymers. Tissue Eng. 2002, 8 (5), 771785 .

(45) Remes, A.; Williams, D. F. Immune response in biocompatibility. Biomaterials 1992, 13 (11), 731-743.

(46) Zachman, A. L.; Crowder, S. W.; Ortiz, O.; Zienkiewicz, K. J.; Bronikowski, C. M.; Yu, S. S.; Giorgio, T. D.; Guelcher, S. A.; Kohn, J.; Sung, H.-J. Pro-angiogenic and Anti-inflammatory Regulation by Functional Peptides Loaded in Polymeric Implants for Soft Tissue Regeneration. Tissue Eng., Part A 2013, 19 (3-4), 437-447.

(47) Lang, K.; Davis, L.; Wallace, S.; Mahesh, M.; Cox, D. J.; Blackman, M. L.; Fox, J. M.; Chin, J. W. Genetic Encoding of Bicyclononynes and trans-Cyclooctenes for Site-Specific Protein Labeling in Vitro and in Live Mammalian Cells via Rapid Fluorogenic Diels-Alder Reactions. J. Am. Chem. Soc. 2012, 134 (25), $10317-$ 10320.

(48) Groll, J.; Fiedler, J.; Engelhard, E.; Ameringer, T.; Tugulu, S.; Klok, H.-A.; Brenner, R. E.; Moeller, M. A novel star PEG-derived surface coating for specific cell adhesion. J. Biomed. Mater. Res., Part A 2005, 74A (4), 607-617.

(49) Raghuram, G. V.; Pathak, N.; Jain, D.; Panwar, H.; Pandey, H.; Jain, S. K.; Mishra, P. K. Molecular mechanisms of isocyanate induced oncogenic transformation in ovarian epithelial cells. Reprod. Toxicol. 2010, 30 (3), 377-386.

(50) Neffe, A. T.; Pierce, B. F.; Tronci, G.; Ma, N.; Pittermann, E.; Gebauer, T.; Frank, O.; Schossig, M.; Xu, X.; Willie, B. M.; Forner, M.; Ellinghaus, A.; Lienau, J.; Duda, G. N.; Lendlein, A. One Step Creation of Multifunctional 3D Architectured Hydrogels Inducing Bone Regeneration. Adv. Mater. 2015, 27 (10), 1738-1744.

(51) Bartneck, M.; Heffels, K.-H.; Pan, Y.; Bovi, M.; ZwadloKlarwasser, G.; Groll, J. Inducing healing-like human primary macrophage phenotypes by $3 \mathrm{D}$ hydrogel coated nanofibres. Biomaterials 2012, 33 (16), 4136-4146.

(52) Gaharwar, A. K.; Schexnailder, P. J.; Kline, B. P.; Schmidt, G. Assessment of using Laponite ${ }^{\circledR}$ cross-linked poly(ethylene oxide) for controlled cell adhesion and mineralization. Acta Biomater. 2011, 7 (2), 568-577. 